\title{
Sojourners Inter-Cultural Communication Competence in Ethiopia: The Case of Amhara National Regional State (ANRS)
}

\section{Mekonnen Hailemariam Zikargae, Bahir Dar University, Nigeria}

\begin{abstract}
The purpose of this research focuses on the sojourners inter-cultural communication competence at the highest tourist destination sites in ANRS,Ethiopia. Qualitative research methodology is employed. Interview and observation are the major techniques to elicit the data. This data is described qualitatively. Thus, the research indicates that there are some opportunities and challenges among sojourners while sojourning and communicating across another culture. They are competent enough during their stay at the sites. But there are some problems of language with the ordinary people as well as misunderstanding and miscommunication. However, the sojourners try to use different mechanisms to adjust themselves with in the new settings to endure with some of the challenges.
\end{abstract}

Keywords :ICC, Competence, Sojourners, Laibela, Gondar, Rock-Hewn 


\section{Introduction}

\section{Background}

It is well known that communication is powerful in all aspects of human life around the world. In every aspect of contexts, people encounter different type of communications with in different channels from different cultural backgrounds in different times and places. Travel that once took months now takes hours. As a result, the world we live in is shrinking. Business dealings that were once confined primarily to local economies have given way to an extensively integrated world economy. Information that once traveled through error-prone and time-consuming methods now appears in the blink of an eye across a wide range of media. In the twenty-first century, people in virtually all locations of the globe are more mobile than ever, and more likely to traverse into cultures different from their own. Consequently, literally and figuratively, the walls that separate us are tumbling down. Though we may not have fully become a "global village," there is no denying that the various cultures of the world are far more accessible than ever before, and that the peoples of these cultures are coming into contact at an ever increasing rate. These contacts ultimately comprise interpersonal encounters. Whether it is the negotiation of an arms treaty, or the settlement of a business contract, or merely a sojourner getting directions from a native people do.

In contemporary world of such global village, the most vital communication in a multicultural society is inter cultural communication i.e. a communication takes place when individuals of different cultural experiences negotiate to have shared meaning in their interaction (Thig-Toomey, 1999). On one hand, it is a communication among individuals from different nations and nationalities (Gudyknust, 2003). On the other hand, it is to encompass inter-ethnic; interregional communication. It is as well as communication among individuals of different ethnic or cultural group (Samovar et al, 2004).

In light of the above concepts, we come to the basic point of this research; inter cultural communication competence (ICC) of sojourners which was deeply assessed. Here what is meant by inter cultural communication competence? One definition of ICC competence is that it is the complex of abilities needed to perform effectively and appropriately when interacting with others who are linguistically and culturally different from oneself. Whereas "effective" usually reflects one's own view of one's performance in the second -language 
culture (i.e., an "etic" or outsider's view of the host culture); "appropriate" relates to how one's performance is perceived by one's hosts (i.e., an "emic" or insider's view). These perceptions often differ, yet they are instructive when compared and contrasted because they arise from differing cultural approaches to the same situation.

Likewise, according to Thig-Toomey (1999) ICC competence is the degree to which an individual is able to exchange information effectively and appropriately with individuals who are culturally dissimilar (Gudykunst, 2003; Samovar et al,2004;Wood,2010). Effectiveness involves achieving the goals individuals have for specific interaction. Individuals are varying widely their skill to communicate with culturally unlike others. Competence also emphasizes appropriateness. This means that competent communication is adapted to particular situations an people. Appropriateness also involves contexts (Gudykunst,2003). One of the most important skills for cultural competence is the ability to suspend our assumptions about what is right and wrong. The greater the range of alternatives to which we are exposed the more choices we have for deciding what makes sense for us knowing another culture gives one places to stand while one take a good at the person one were born in to.

Accordingly, being ICC competent is an extent of capability of individuals to communicate successfully with culturally different people. Cultural difference including is one reason for being a sojourner because individuals curious to know the different culture that they cannot show in their surroundings. For this reason I intended to assess the ICC competence of sojourners as well as in tourist attraction centers of Ethiopia the case of Bahir Dar City, Lake Tana , Gondar and Lalibela. Gondar and Lalibela are the typical and famous among UNESCO heritages in the world.

Though the above all explanations are to come up to the basic point of this research that is sojourner and dweller ICC competence. A sojourner is an individual who visits another culture for a short or long term period but who returns to his her original culture. The sojourner typically is a visitor or a traveler who only resides in the other culture for relatively specific time often a month, year or two, with the intention returning home. Sojourners may be business people, diplomats, students, intellectuals, military personnel, or guest workers. 
For instance, when we come to the case of Bahir Dar's,Gondar and Lalibela the sojourners mainly tourists, and annually the tourists are counted with thousands of people as the report (2003) of the regions tourism office. According to the report the tourist that come with six months are 5140 in average for every year.

To this end, the purpose of this research is to examine the ICC competence in inter cultural contexts. For the purposes of this research, ICC is considered very broadly as an impression that behavior is appropriate and effective in a given context. So does the communications. Normally, competence is considered ability or a set of skilled behaviors that needs developing a range of communication skills. However, any given behavior or ability may be judged competent in one context, and in-competent in another. Consequently, competence cannot inhere in the behavior or ability itself. It must instead be viewed as a social evaluation of behavior. This social evaluation is composed of the two primary criteria of appropriateness and effectiveness. Hence, these are the main concern of this research.

\section{Statement of the Problem}

Unlike competing different kind of communications ICC competence, which is done by sojourners with the surrounding people is then one. Such as their competence to communicate well as much they capable as possible, the time and the place where their competence done, the difficult conditions of their communication may be insufficient ability of speaking or bare use of local language ,cultural shock etc... Culture shock, for instance, is a common stress reaction that individuals have when they find themselves immersed in an unfamiliar culture. Little about the basic question of this research, sojourners ICC competence in tourist attraction centers of Ethiopia, particularly the Amhara National Regional State(ARNS).

Competence is an influential thing on every activity of sojourners and the local community or society, so that their opportunities and challenges of ICC competence are worth researching. The focus of this research is to identify the inter cultural communication competence challenges and opportunities of sojourners and the dwellers and find out factors that are barriers and enhancers to their competence in various aspect and perspectives with specific reference to Bahir Dar city(Lake Tana), Gondar and Lalibela sites. To make it specific we focus around visiting areas, residences, marketing, and recreation. And what they eat as well. Their expectations before arrival and actual exposure after arrival. How they communicate? 
The language they employ during interactions with the local people. What they are experiencing being here in Ethiopia? So what they will do up on returning to their home.

Generally, this research found out the various difficulties that the sojourners in their life being stranger; like cultural shock, language problem, food habits, fear, misunderstandings, mis-communications and other interactions related problems.

\section{Objectives of the Study}

The general objective is to study the sojourners ICC competence in the tourist attraction centers of Ethiopia particularly with the focus of the above mentioned tourist sites. Within the general objective there are also various specific objectives which stated as follows;

- To point out the challenges sojourner face on their ICC competence.

- To explore the opportunities they get from the interactions that enhance the development of tourism.

- To identify the competence that sojourners and local people have.

- To accumulate the major benefit that the sojourners and local people gain from their interaction competence.

- To evaluate ineffective cultural communication that may lead to cultural clashes.

- To determine how better ICC competence can contribute to the development of truism industry in Ethiopia.

In accordance with the specific objectives mentioned here, the research addressed one basic research question:

\section{What are the opportunities and challenges of sojourners and surrounding people ICC competence in Ethiopia with particular reference to ANRS tourist sites?}

\section{Significance of the Study}

The sojourners inter cultural communication competence in the tourist sites have opportunities and challenges on their sojourning. Therefore, identifying the kind of competence in which the sojourners have in contexts could be significant to the people of the city specially who have contact with sojourners and their activities, for individuals who want to know about the sojourners communication competence as knowledge of communication skill and for the use of literature reference to other research workers in relation to this 
research area.To carry out further study in wide scale and depth the result of this study may be expected to create opportunity to:

> Cultural awareness, knowledge, understanding, sensitiveness, motivation and skills to both the sojourners and the inhabitant.

$>$ The acculturation of sojourners.

$>$ Intervention that can increase intercultural sensitivity and reduce cultural misunderstandings.

> Contribute and expand the growing corpus of research into how the communication sciences can contribute to peace and stability in the world.

> A safe context for inter-cultural or cross- cultural interaction.

> Establish inter-cultural or cross-cultural understanding and world peace that lead inter-cultural or cross-cultural sojourning as a way to the peaceful world.

> Build a favorable environment for living together successfully in the coming century.

> Provide initial step-training for those who need to maximize the tourism sector.

\section{Scope of the Study}

The research limited to the interactions of sojourners with dwellers of Bahir Dar City(Lake Tana), Gondar and Lalibela contexts. By sojourners we mean that those who come from abroad counties for the purpose of touring in Ethiopia. In other words, the main purpose of this research is to find out the communication activities (both challenges and opportunities) of the sojourners in the given multicultural setting or contexts. Hence, the scope is delimited to sojourners in the tree specific tourist sites.

\section{Theoretical Framework}

\section{Definitions and Some concepts}

In today's world of global village, living with differences both at home and abroad is becoming more important. Differences such as values, attitudes, culture, ethnicity, social practices, political beliefs, sexuality and religion clearly direct people all around the world who embarked various meanings to their surroundings according to their individual attitudes that must be fully respected and integrated into life. 
Learning to deal with different cultures effectively requires cultural awareness, communicative competence, personal attitudes like empathy and flexibility, self-awareness and understanding others values, norms and beliefs. Communication is interaction of individuals, organizations, markets and countries with each other for sharing information to reach a common understanding. ICC competence on the other hand is defined by Chen (1990) as "the ability to effectively and appropriately execute communication behavior to elicit a desired response in a specific environment". Thus, the combination of inte-rcultural competence and communication competence; hence, ICC is defined by Chen and Starosta (1996: 358-9) as "the ability to effectively and appropriately execute communication behaviors that negotiate each other's cultural identity or identities in a culturally diverse environment". This definition emphasizes that competent persons must know not only how to interact effectively and appropriately with people and environment, but also how to fulfill their own communication goals by respecting and affirming the multilevel cultural identities of those with whom they interact. Some others also define as it is the sending and receiving of messages across languages and cultures to communicate and share knowledge. It is also a negotiated understanding of meaning in human experiences across social systems and societies. ICC is also defined by Wiseman (2001) as the comprised form of knowledge, skills, and motivation necessary to interact effectively and appropriately with individuals from different cultures where motivation is made an element of ICC competence. The summary of the literature survey regarding the components of ICC competence is summarized in the model given in Figure 1. 


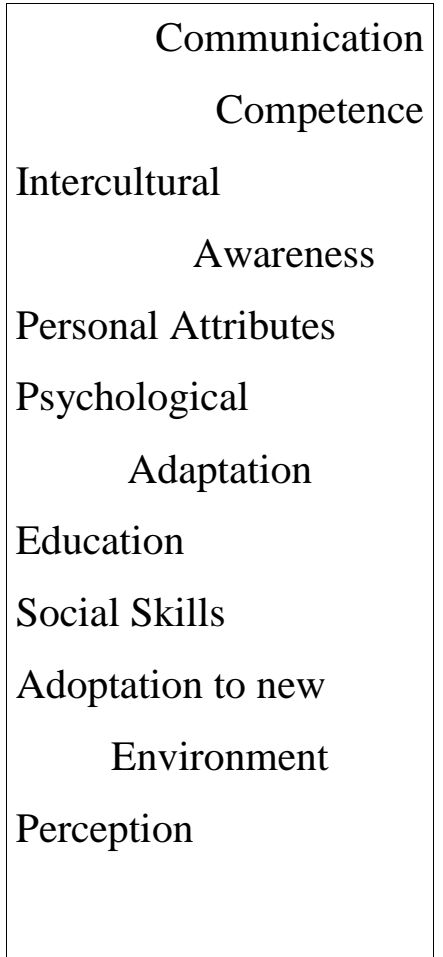

Figure 1.The components of ICC

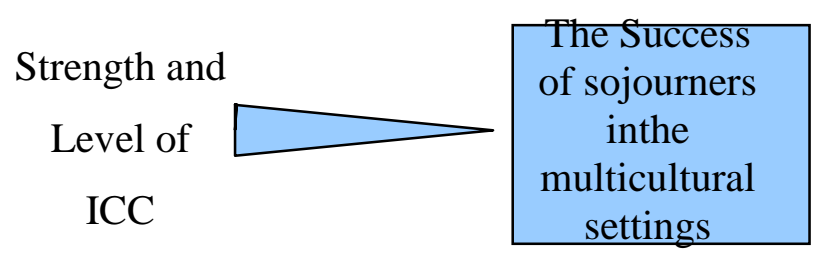

Competence

\section{ICC Competence}

\section{Defining ICC Competence}

Spitzberg says that ICC competence in its most unadorned form is simply "behavior that is appropriate and effective in a given context"(cited in Samovar et al,2010:384). Gudykunst (2003) and Wood (2010) offers a more detailed definition when he notes that ICC competence is the overall internal capability of an individual to manage key challenging features of ICC: namely, cultural differences and unfamiliarity, intergroup posture, and the accompanying experience of stress. What these definitions tell us that being a competent communicator means having the ability to interact effectively and appropriately(Gudykunst,2003;Wood,2010) with members of another linguistic-cultural background on their terms.

\section{Components of ICC Competence}

Empathy and being a good listener, which are associated with interpersonal communication competence. Most of the research in the area of ICC competence reveals five components of competence that influence one's ability to interact effectively and appropriately in another culture. These are (1) motivation to communicate, (2) an appropriate fund of cultural knowledge, (3) appropriate communication skills, (4) sensitivity, and (5) character 


\section{Methodology}

\section{Research Design}

In ICC research methods it is well known that ICC is influenced by many social science disciplines such as Anthropology, Cross-Cultural Psychology, Linguistics, Communication, Sociology and Philosophy (Harman \& Briggs, 1991; Hart, 1999; Hu, 1999, 2004; Samovar et al., 2004), which ICC scholars identified as the interdisciplinary characteristics. In fact, some scholars have conducted meaningful research to demonstrate the interdisciplinary characteristics of ICC. For instance, Harman and Briggs' study (1991) and the study of Hart (1999) demonstrates the dominant influence of Psychology, Anthropology and Linguistics on ICC research. As ICC is a mixture of many social science disciplines, the methods to conduct ICC research are various. As a matter of fact, there is no fixed pattern for the research methods of ICC ( Korzenny \& Korzenny, 1984).

Multi-method in focus, has involving an interpretive, naturalistic approach to its subject matter. This means that qualitative researchers study things in their natural settings, attempting to make sense of, or interpret phenomenon in terms of the meanings people bring to them. Qualitative research involves the studied use and collection of a variety of empirical materials, case study, personal experience, introspective, life history, interview, observational, historical, interactional, and visual texts that describe routine and problematic moments and meanings in individuals' life.

As ICC is a mixture of many social science disciplines, the methods to conduct ICC research are various. As a matter of fact, there is no fixed pattern for the research methods of ICC ( Korzenny \& Korzenny, 1984). As a multidimensional ICC research has adopted the methods preferred by scholars with different academic backgrounds. Linguists collect specific language data to reveal problems that appear in the process of ICC, and communication scholars are interested in the exploration of theories about ICC. When studying ICC, it is recommended by some scholars (e.g., Chen \& Starosta, 1997; Hu, 2004; Korzenny \& Korzenny, 1984) that more than one method be adopted to achieve a comparatively more complete result. As there is no definite research method for ICCresearch, it is held that the empirical nature of any kind of research, be it intercultural or not, is just the 
same (Hu, 2005) and the traditional qualitative methods used in social science research are also applied to the study of ICC (Korzenny \& Korzenny, 1984).

Based on current research experience, the classification of ICC research methods appears to fall within empirical research. According to Bachman (2004), empirical research refers to an activity in which the researcher observes some phenomenon in the real world, interprets it in some way, and then uses this interpretation to reach a decision or generalization about the research. In the ICC context, it requires researchers to observe how people with different cultural backgrounds interact with each other, both verbally and nonverbally, and interpret the results of these observations in a way that is meaningful to the field. To make it simple, empirical research is data-based, characterized by systematic collection and analysis of data (Gao, Li,\&Lü, 2001; Hu, 2005); followed by a comprehensive conclusion summarizing the research.

Therefore, qualitative research method is modern-day modes of doing research in ICC; It falls into the category of empirical research. McDonough and McDonough (2000) distinguish qualitative research as interpretive (in contrast to normative) research. According to some scholars (e.g., Gui \& Ning, 1997; Malhotra, 1993; Reichardt and Cook, cited in Nunan, 1992) qualitative research includes detailed descriptions of collected data from a holistic, natural perspective. It also, essentially, qualitative research aims to capture lived experiences of the social context and the meanings people give these experiences from their own perspective.

Second, according to these scholars, qualitative research often makes naturalistic observation to collect data because qualitative researchers believe any handling or interference in the research context that would distort the nature of the data, which would eventually affect the collection, interpretation, and presentation of the data. Third, qualitative designs are often used to achieve different objectives. Qualitative research is inductive (in contrast to deductive) because the research investigation progresses from the general to the specific (unlike quantitative). Researchers develop concepts, insights and understandings from patterns in such data as interviews, diaries and recordings. Since the research question is suggested by these returning patterns which emerge from the data itself. In the initial stages of qualitative research, the researcher will enter the research context without a particular focus and try to consider the data in an open manner. At the end, some narrowing of focus is 
necessary as the research progresses and the research question crystallizes, so qualitative research is viewed as an organic development (Seliger \&S hohamy, 1999) and to some degree the process is synthetic and dynamic. In summary, the methodology favored to be used in this research is qualitative.

\section{Sampling Techniques}

The sample size (Mekonnen, 2010) decisions are a bit more dynamic in qualitative research than in quantitative research. Hence, the number of observation is not determined in the former type of research prior to data collection. The researcher should select the persons, places and events under study. The optimum sample size is related to the type of research we are undertaking. Van de Vijves and Leung (1997b) isolate three possible sampling methods: Convenience, systemic, and random.

Most qualitative inter-cultural or cross-cultural studies use samples of convenience (Gudykunst, 2003), rather than random sample. Because convenience samples are as equivalent as possible is to gather as much data on the respondent that is relevant to the study. For example, the intimacy of the in-group and out-group relationships and frequency of contact with in-group and out-group members should be assessed. As a result, random sampling, generally are not feasible in inter-cultural or cross-cultural research and in this research as well.

\subsection{Data Collection Methods}

The data source consists of both primary and secondary data. To elicit primary data, the researcher used interview, observation and questionnaire (mostly open ended questions will be administered). Whereas, secondary data can be elicited from press releases, conference speeches, videos, audios, pictures, manuals, policies, research outcomes and other documented materials whenever available.

\section{Data Analysis}

The methodology of data analysis is qualitative. This is due to the nature of the study that it seeks to be seen qualitatively. Qualitative research is described as "the non-numerical examination and implementation of observation, for the purpose of discovering underlying meaning and patterns of relationships"(Richie \&Lewis,2003 cited in Yohannes,2009:19).The major aim of qualitative research is to provide a perspective of a situation and present well- 
written research reports that reflect the researcher's ability to illustrate or describe the corresponding phenomenon. One of the greatest strength of the qualitative approach is richness and depth of explanations and descriptions. As qualitative research is fundamentally interpretive, the analysis for the study could be interpretation analysis that uses thematic analysis. This includes developing description of an individual or setting, analyzing data for themes or categories and finally making an interpretation drawing conclusions about its meaning.

\section{The Sojourners' ICC Competence in ARNS}

The ICC effectiveness and appropriateness of tourists of selected tourist sites obvious as of other cultures, they try to compete to find the fruits of communication in diversified society. Tourists communicate with people for their different activities in selected sites with their maximum communication ability. As they stated the purpose of sojourners to communicate are, as they need help for ways of the new culture and so forth. The same is true in the study settings. They possibly communicate for whatever they need, in whatever conditions, for whatever kind of person with different comfortable manners for the conditions where they are in. But most of communicators in time their communication are guiders, waiters,shop keepers, taxi drivers and co-workers of drivers and other people in the city with in different situations in their respective time and place. They have good communication with guiders because the guiders are better language knowledge and they are adapted with many diverse strangers behavior in their long time experience. This helps them to create a good communication environment even with others and they can be able to be effective and appropriate on the communication with new culture of the sites.

According to one of the interviewees from England, the communication they made with the people in the sites are very nice because the people are interested to communicate with them. This makes them to intimate more with the people and do not be fear and confused. The people's interest and the sense of helpfulness give many opportunities to them to communicate in competent manner. The tourist points out that anything needs to be easy and polite manner and culturally sensitive for both communicators. They put a lot of efforts to make their communication effective and appropriate as if they touring and sharing beliefs and norms. 
We are traveling different culture to communicate, share and experience their culture, so we make ourselves ready to feel the new environment, food,language, and the new culture's people and the reasons why we are traveling and we need to be appropriate effective, of course this is also true here(the tourist from England).

The tourist's communication can influence the tourism activity of the sites to be good or bad with regard of their ICC competence and the people's interactive manner in the tie of diversification.

\section{The Components of ICC Competence for the Tourists}

The tourists are motivated to communicate with the people who intimate them to talk with them with whatever intention. They need to communicate to relate with the people, to know about the culture, to share different experience and even to learn the language of the society i.e. Amharic.

They have knowledge of major things of Ethiopia and also the tourist sites by referring books and if not, they try to know gradually in staying to the culture, because this helps them to do not be new and confused when they firstly enter to the culture of the country as well as the sites. And they are skillful to how to communicate with every new culture. They know how to behave, how to talk and when to talk, what is acceptable and unacceptable, what shows respect and disrespect in the communication not only in the sites but also every place they go worldwide. Being a good person is their ultimate aim in their journey to different culture and society everywhere they go and here also, because they can get the best of people response for every request of them. It is true that good character honorable not even for communication only it is for all aspects of life in the new culture of the settings.

As one of the interviewees who is from Germany said that;

Yes, I am interested, that is why I am traveling across boundary to meet different people, culture, and to share their culture have knowledge a bit but I will learn as long as am here. I know how to act here and am respectful and worth even for my clothing, when I am here. I think I am good for people up here because I have to, here being polite, tolerant and friendly is necessary for our communication. 


\section{Ways of Competence}

One or another becoming competent is must for good ICC in every new culture and also here. First and for most one should be emphatic,adaptive,aware of his own culture, respectsdiversity, uses flexible communication, and monitor oneself. These all ways workable for the sites tourists, they try to show empathy for all that need this, they help for they are affordable, andgive advice at the time when it needed in the communication with people of the city.

Adjustment or adaptation of the culture is on way for tourists they adjust their behavior but not changing their original one for the purpose effective communication. They are flexible in their communication in what so ever communication situations. They respect the difference between them and their int-ractants even they appreciate the diversity. http://www.ethiosports.com/2011/01/02. They are too much aware of their culture, what is good and bad, right and wrong, acceptable and unacceptable, and so forth. Self-monitoring is a little bit difficult in a new culture but they monitor themselves as if it is possible.

You have to understand their culture, because they are different from me, so I try to feel what is their culture seems and what are their emotions. Definitely I change my behavior what in my original culture but not completely just little adjustment (from Taiwan).

I love diversity because I live with highly diversified environment and I love to meet with different people, I want to know diverse culture, languages and to learn more about the world(from USA).

I try to look myself what I am doing and monitor myself on my communications (From Canada).

\section{Opportunities}

The opportunities are sharing new ideas, different thinking and beliefs, knowing language, learning different life aspect and experience, dressing style, food, culture and so forth. Sharing one to other about different activities, needs, beliefs, norms, customs and many more are the opportunities for the tourists of the sites.

Touring and meeting different people like I am here,helps me to learn lot about their culture in general and their languages,beliefs,norm,customs,dressing style and other pattern of their life. I can see different things that I cannot see in my culture. To meet 
people from different culture makes me know what is around the world and looks like the culture environment outside countries. It makes me knowledgeable enough about the world entirely (from England).

Besides, there are different special events which could be celebrated at different times. These actual setting celebrations are one of the opportunities that enhance tourists' engagement in visiting as well as participating in the sites. They thought that they want to visit the sites again during a special event celebrations. They were inspired to communicate the cultural aspects in addition to the other features of the sites to the other world friends as well as potential tourists in the rest of the world. We can look at the following scenario:

\section{Scenario}

This morning we will visit the first cluster of amazing rock- hewn churches another UNESCO World Heritage Site - that will simply stagger you. After lunch, we will visit a local family for a traditional coffee ceremony where you will be able to see how a real Ethiopian family live.

TESFA Village Walk: After a further look at some of the remaining churches, we'll drive to the start of our village walk. This is sure to be a real highlight of the trip and is an opportunity not currently offered (to the best of our knowledge) by any other UK tour operator as part of a group tour. In conjunction with our friends at TESFA (Tourism in Ethiopia for Sustainable Future Alternatives) we undertake a fascinating walk visiting local communities and staying in traditional villages. Please note that during these days, depending on the group size, it may be necessary to divide into two groups (one with the tour leader; one with the Ethiopian guide) - this is to minimize the impact of our presence in these communities. It will also allow for a more personal \& intimate experience for everyone. Both groups will visit the same villages (but in a different order), meeting up at the start, middle \& end. Most walking is at around $3000 \mathrm{~m}$ and as everyone should be fairly well acclimatized by now, anyone of reasonable fitness should be fine with it. The walks vary in length from 4-6 hours with the emphasis being very much on seeing the people \& countryside rather than rushing through it(from England). 


\section{Challenges}

The feeling of fear always occurs at the time of joining new environment. Becoming uncertain is also true for a new arrival. Besides, in the new environment, the unfamiliarity of the communication setting is also hampers the communication in general. The problem is when it affects the individual's well-being in the new environment. These problems also occurred for the tourists of the sites when they entered, because here also things are new, but exceptional cases are happen there are people that have nature of smoothness for every condition. That is re-adjustment and adaptability.

The feelings of stereotype and prejudice are for the tourists both in their side and in the people. People of the sites think that people with white skin are rich superior from them and some other developed hate on them which catchable cause and some the tourists I observe have shown the feeling of racism. This interrupts the communication environment. The strangers sometimes face neglectful communication from the society of the sites in various aspects like when the society thinks they are not part of us and they think that the tourists not volunteer to communicate because they are whites.

The main and the most visible challenge for tourists is language, which creates miscommunication, misunderstanding, and misleading and even it makes them not to communicate.

I have language too much, and the other the people's thinking about as is challenging they think that we have lots of money because we do have white skin and they always say give me money in different streets(from Norway).

I have made assumptions before I come here about thing but many things are so different. I think that there is little difference from mine but the communication style even the languages are too much new for me(from China).

\section{Conclusion and Recommendation}

This research has the main objective to analysis of the sojourners ICC competence. The conclusion and recommendation are as follows;

\section{Conclusion}

1. The tourists are too much competent in their communication that they are flexible,friendly manner and respectful of the culture and norms of the society. 
2. They are too much eager of knowing the things here, and they are free to communicate with anybody who meets them for every purpose like I do;it means that they need to help everybody.

3. The tourists are benefited in their communication they can what seems like cultures of the local.

4. Society in the sites has developed stereotype, and ethnocentrism towards the sojourners.

5. The forms of communication between the society and tourists are not smooth as the researcher expected and the tourists forced or geared their communication towards to make them comfortable for all communication to be as much as possible to comfortable.

6. They have fear of moving from place to place because unsafe condition of thief.

7. They have a problem of adapting the environment because of lack of cleanness and this makes uncomfortable to move as they need and to communicate with different communities of the sites.

8. The tourists are unable to communicate clearly in the hotels during they need services.

\section{Recommendation}

1. The society need to have change attitude towards the tourists no matter there is color differences.

2. There must be creating comfortable communication conditions as if they are our guests and the sources of income for the country,Ethiopia.

3. There must be open and safe conditions for by providing accessibility and protection.

4. The environment has to be clean in every aspect not only for them but also for the society itself.

5. The guiders has to be trained how to accept strangers, in what manner and context to make the communication sphere smooth and easy to strangers.

6. An ICC competence continuum training should be adopted.

7. ICC guidelines for the guiders,stakeholders and the tourists should be developed.

8. Language learning centers for the hotels in the sites should be established. 


\section{References}

---------. (204). Crossing cultural barriers. Beijing: Foreign Language Teaching and Research Press.

----------. (2005). On Empirical Research of Intercultural Communication. Foreign Language Teaching and Research, 37(5), 323-327.

Bachman, L. (2004). Research Guidelines in TESOL: Alternative perspectives. TESOL Quarterly, 38(4), 723-734.

Chen, G. M., \&Starosta, W. J. (1997). Foundations of intercultural communication. Needham Height, Mass: Allyn \& Bacon.

Gao, Y. H., Li, L. C., \&Lü, J. (2001). Trends in research methods in applied linguistics: China and the West. English for Specific Purposes,20(1),114.

Gudykunst.(Ed).2003.Cross-Cultural and Intercultural Communication. Thousand Oaks: Gui, S. C., \& Ning, C. Y. (1997). Linguistics research methods. Beijing: Foreign Language Teaching and Research Press.

Harman, R., \& Briggs, N. (1991). SIETAR Survey: Perceived contributions of the social sciences to intercultural communication. International Journal of Intercultural Relations, 15(1), 19-28.

Hart, W. (1999). Interdisciplinary Influence in the Study of Intercultural Relations: A citation analysis of the International Journal of Intercultural Relations.

Hu, W. Z. (1999). Outline of Intercultural Communication. Beijing: Foreign Language Teaching and Research Press.

Korzenny, F., \&Korzenny, B. A. G. (1984). Quantitative Approaches: An overview. In W. B. Gudykunst, \& Y. Y. Kim (Eds.), Methods for intercultural Communication research (pp. 85-94). Beverly Hills, CA: Sage.

Malhotra, N. K. (1993). Marketing research: An applied orientation. New Jersey: PrenticeHall. Inc.

McDonough, J., \& McDonough, S. (2000). Research Methods for English Language Teachers. Beijing, China: Beijing Foreign Language Teaching and Research Press. Mekonnen Hailemariam. (2010). Cognition and Affect in Cross-Cultural Communication: The Case of Addis Ababa University.U.S.A:VDMVerlag.

Neuman, W. L. (2003). Social research methods - qualitative and quantitative approaches (5th ed.). Boston: Allyn and Bacon.Y. Hu, W. Fan / International Journal of Intercultural Relations 35. (2011) 554- 566 
Nunan, D. (1992). Research Methods in Language Learning. New York, NY, USA:

Cambridge University Press.

Samovar et al. (2000).Communication between Cultures. Beijing: Foreign Language Teaching and Research Press.

Ting-Toomey, S. (2004).Communicating across Cultures. New York: The Guilford Press.

Wiseman, R. L. (2002). Intercultural Communication Competence. In W. B. Gudykunst, \&B.

Mody (Eds.), International and Intercultural Communication (2nd ed., pp. 207- 224).

Thousand Oaks, CA: Sage. 